\title{
A Study of the Mechanical and Thermal Characteristics of an Al-Si-Fe Alloy Fabricated by Rolling and Heat Treatment
}

\author{
Yu Guo ${ }^{1}$, Ye Wang ${ }^{1, *}$, Jieren Yang ${ }^{2, *}$, Hongyu $\mathrm{Xu}^{1}$, Maoliang $\mathrm{Hu}^{1}$ and Zesheng $\mathrm{Ji}^{1}$ \\ 1 School of Materials Science and Engineering, Harbin University of Science and Technology, \\ Harbin 150004, China; guoyuhrbust@163.com (Y.G.); xuhongyu@hrbust.edu.cn (H.X.); \\ humaoliang@hrbust.edu.cn (M.H.); jizesheng@hrbust.edu.cn (Z.J.) \\ 2 State Key Laboratory of Solidification Processing, Northwestern Polytechnical University, \\ Xi'an 710072, China \\ * Correspondence: wangye1984@hrbust.edu.cn (Y.W.); yangjieren@nwpu.edu.cn (J.Y.); \\ Tel: +86-0451-8639-2557 (Y.W. \& J.Y.)
}

Received: 20 November 2018; Accepted: 18 December 2018; Published: 21 December 2018

check for updates

\begin{abstract}
The effects of a rolling process and heat treatment on the mechanical and thermal properties of an Al-Si-Fe alloy were studied. The achieved thermal conductivity of the as-rolled alloy treated by a T6 heat treatment was $188.22 \mathrm{~W} /(\mathrm{m} \cdot \mathrm{K})$, which is as good as that of the as-cast alloy treated by the $\mathrm{T} 6$ heat treatment directly, mostly because of changes in the silicon morphology. The results also revealed that the lower quantity of precipitated $\mathrm{Al}_{8} \mathrm{Fe}_{2} \mathrm{Si}$ and $\mathrm{Mg}_{2} \mathrm{Si}$ phases had no obvious effect on the thermal properties of the material because the interphase spaces between precipitated phases were larger than the mean free path of electrons. However, the precipitated second phases influenced the elongation. The best mechanical properties of the Al-Si-Fe alloy were obtained by rolling and T6 treatment. The corresponding best tensile strength, yield strength, and elongation were $244 \mathrm{MPa}, 295 \mathrm{MPa}$, and 9.56\%, respectively, which are attributed to the near-spherical shape, small size, homogeneous distribution of the Si particles, and the precipitation strengthening of $\mathrm{Mg}_{2} \mathrm{Si}$.
\end{abstract}

Keywords: rolling; heat treatment; microstructure; thermal conductivity; Al-Si-Fe alloy

\section{Introduction}

With increasing demands to replace ferrous alloys with lightweight alloys, Al-Si alloys are being extensively used in automotive, aerospace, and various other applications due to their low densities, acceptable mechanical properties, and good wear resistances [1-3]. Generally, Fe is inevitably adulterated in the production of Al-Si alloys. Al-Si alloys with $\mathrm{Fe}$ and $\mathrm{Mg}$ additions are widely used for engine blocks, cylinder heads, and heat sinks due to their excellent fluidity and thermal expansion ability [4,5]. Furthermore, these elements have less of an effect on electron scattering in electronic transmission [6]. Thermal properties play an important role in certain applications, so aluminum alloys with high thermal conductivity have become a candidate for heat sink applications. Although solid solubility has a great influence on the thermal conductivity of alloys, Lumley et al. [7] treated die cast alloys by using a T7 temper and reported that the thermal diffusivity and thermal conductivity of the alloy increased. Chen et al. [8] suggested that precipitation and heat treatment could influence the thermal conductivity of aluminum alloys by experimentally and computationally investigating binary and ternary $\mathrm{Al}$ alloys. Thus, many researchers have attempted to enhance the thermal properties of aluminum alloys by various heat treatments.

Choi et al. $[9,10]$ investigated the effects of the cooling rate and different heat treatments on the thermal properties of an Al-Si-Cu-Mg alloy, and the results revealed that the tensile strength and 
thermal diffusivity of the alloy could be improved by breaking down and then gradually spheroidizing the long needles of silicon. In addition, a higher aging temperature further enhanced the thermal conductivity of the Al-Si-Cu-Mg alloy. By studying the thermal diffusivity behavior of $\mathrm{Al}$ alloys with silicon contents of $1 \mathrm{wt} \%$ and $9 \mathrm{wt} \%$ according to the heat treatment, Kim et al. [11] suggested that the thermal diffusivity increased as the dissolved silicon atoms in the matrix decreased. The thermal conductivity of the solution-treated Al-4.5Cu alloy was lower than that of the same alloy after the artificial aging treatment [12].

Theoretically, an increase in the number of alloying elements will reduce the thermal diffusivity of the alloy, and the thermal conductivity would decrease to a greater extent when the elements are dissolved in the matrix [13-15]. Therefore, higher thermal properties are achieved by changing the size of the precipitated phase through heat treatments, such as the refined and spheroidized precipitation of the secondary phase that is obtained by T6 treatment $[16,17]$. The increase in conductivity is primarily due to a decrease of solutes in solid solution associated with the fine precipitation, as expected $[13,14]$.

Considering that shape deformations, including rolling and extrusion, can weld the defects of shrinkages or porosities and effectively break the second phases into finer particles [18-20], studies on the effects of rolling and heat treatment on the thermal properties of Al-Si-Fe alloys have rarely been reported. For the past few years, little attention has been paid to the change of thermal properties that is induced by microstructural evolution of the Al-Si-Fe alloy. So, it is necessary to look for an ideal method for Al-Si-Fe alloy, which not only has good mechanical properties but also keeps good thermal conductivity to some extent. Thus, the main purpose of this work was to demonstrate the advantages of rolling and heat treatment for the improvement of strength and thermal conductivity of Al-Si-Fe alloys. The effects of rolling and heat treatment on the microstructure, thermal conductivity, and mechanical properties of an Al-Si-Fe alloy are examined in this paper.

\section{Materials and Methods}

The alloys used in the present study were melted in a graphite crucible in an electrical furnace. The chemical composition of the present alloy is listed in Table 1. A steel mold was preheated to $475 \mathrm{~K}$, and the melt was poured at $998 \mathrm{~K}$ after refinement was implemented with $0.5 \% \mathrm{C}_{2} \mathrm{Cl}_{6}$. The Al-Si-Fe alloys were subsequently cut into dimensions of $150 \mathrm{~mm} \times 100 \mathrm{~mm} \times 8 \mathrm{~mm}$ for milling from the center of the ingots, homogenized at $783 \mathrm{~K}$ for $12 \mathrm{~h}$, and then cooled inside of the furnace to room temperature before rolling. The rolling process was carried out by a double roller mill at $753 \mathrm{~K}$ four times, with a total rolling reduction of $71.25 \%$. Before each pass, the samples were placed in a resistance furnace at $753 \mathrm{~K}$ for $30 \mathrm{~min}$ to ensure a constant temperature throughout the process. The rolling process of the Al-Si-Fe alloy is schematically presented in Figure 1. In addition, the as-cast samples and as-rolled sheets were subjected to a solution treatment at $788 \mathrm{~K}$ for $8 \mathrm{~h}$ followed by water quenching, and then artificial aging was performed at $443 \mathrm{~K}$ for $6 \mathrm{~h}$ and then cooled in air.

Table 1. Chemical compositions of Al-Si-Fe alloy, wt $\%$.

\begin{tabular}{cccccccc}
\hline Si & Fe & Mg & Ni & Mn & Zn & Others & Al \\
\hline 11.38 & 0.403 & 0.2352 & 0.0507 & 0.0156 & 0.0138 & 0.007 & Bal. \\
\hline
\end{tabular}

Then, samples for microstructural observation were examined by an optical microscope (OM) (Leica Microsystems Inc., Wetzlar, Germany) and quantified with an image analyzer (Image pro plus), (Media Cybernetics, Inc., Rockville, MD, USA). Ten images of each sample were examined, and the magnification of images was $400 \times$. The OM samples of the as-cast and as-rolled alloys-with or without T6 heat treatment-were cut from the center of the casting ingots and rolling sheets (i.e., the ND (normal direction) plane of the as-rolled specimens, as shown in Figure 1, and the plane perpendicular to the direction of gravity of as-cast samples), and were ground, polished, and etched 
by hydrofluoric acid (HF) for observation. The size of the specimens was $10 \mathrm{~mm}$ in length by $10 \mathrm{~mm}$ in width.

(a)

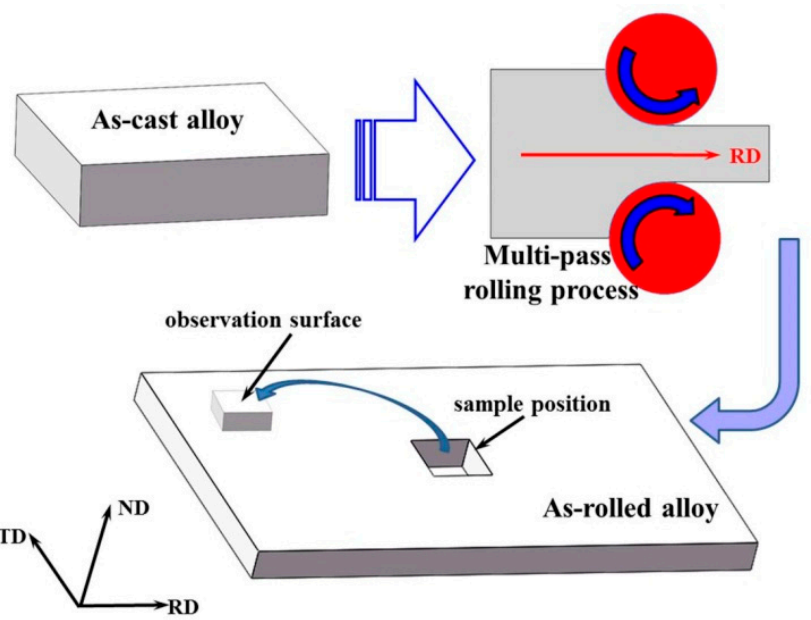

(b)

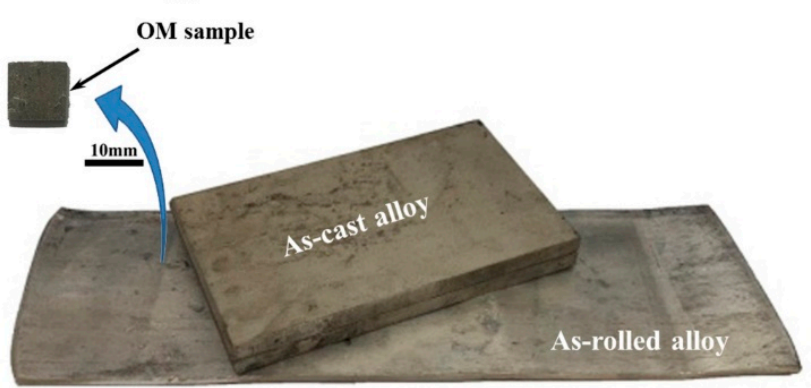

$50 \mathrm{~mm}$

Figure 1. A schematic diagram (a) and real samples (b) of the rolling process and position of the optical microscopy $(\mathrm{OM})$ samples obtained from the as-rolled Al-Si-Fe alloys. ND: normal direction, TD: transverse direction and RD: rolling direction.

The thermal diffusivity and specific heat capacity were measured by a NETZSCH LFA 447 Analyzer (NETZSCH, Wittelsbacherstraße 42, 95100 Selb, Germany) at room temperature. During testing, liquid nitrogen was used to reduce the temperature, which was increased by laser pulse, to ensure the samples were at constant temperature. For thermal diffusivity and specific heat capacity tests, $0.76 \mathrm{~g}$ disc-shaped samples with dimensions of $\Phi 12.7 \mathrm{~mm} \times 2.3 \mathrm{~mm}$ were prepared perpendicular to the rolling direction by electrospark wire-electrode cutting, and then spray-coated with carbon powders to prevent the reflection of the laser. The flash method to test the thermal diffusivity of solids was based on the ASTM E1461 standard. The specific heat capacity was measured by the comparison method. The results of thermal diffusion coefficient and specific heat capacity could be obtained simultaneously through the NETZSCH LFA 447 Analyzer. The material of the reference sample was pure aluminum provided by NETZSCH. At least three shots were performed in each sample. The bulk density of the samples was measured based on the Archimedes rule by a FA1004N electron balance. Thus, the thermal conductivity, $\lambda$, could be calculated by the following formula:

$$
\lambda=a \cdot \rho \cdot \mathrm{C}_{p}
$$

where $a$ is the thermal diffusivity $\left(\mathrm{m}^{2} / \mathrm{s}\right), \rho$ is the density $\left(\mathrm{g} / \mathrm{cm}^{3}\right)$, and $\mathrm{C}_{p}$ is the specific heat capacity $(\mathrm{J} /(\mathrm{kg} \cdot \mathrm{K}))$. Tensile tests were measured at least three times by an INSTRON 8861 universal material test machine with an initial strain rate of $1 \mathrm{~mm} / \mathrm{min}$ at room temperature. The test specimens of as-rolled and as-rolled with T6 treatment were cut along the rolling direction. The fractographs of different processes were obtained by a scanning electron microscope (SEM). 


\section{Results}

\subsection{Microstructures}

Figure 2 shows the metallographic images of Al-Si-Fe alloys prepared by different processes. The main phases in the Al-Si-Fe alloys were composed of $\alpha-\mathrm{Al}, \mathrm{Si}$, and $\mathrm{Al}_{8} \mathrm{Fe}_{2} \mathrm{Si}$. Typical needle-shaped eutectic silicon, block-shaped primary silicon, and "Chinese-script"-shaped $\mathrm{Al}_{8} \mathrm{Fe}_{2} \mathrm{Si}$ precipitates [21] were present in the as-cast Al-Si-Fe alloy, as illustrated in Figure 2a. The bright primary silicon phase was much less abundant than the dark eutectic silicon precipitates, which can always be observed in as-cast Al-Si-Fe alloys [22]. The eutectic Si nucleated heterogeneously on the earlier precipitated $\mathrm{Al}_{8} \mathrm{Fe}_{2} \mathrm{Si}$, as shown in the enlarged area of Figure 2a. Furthermore, both primary and eutectic silicon had a rough interface with the aluminum matrix.

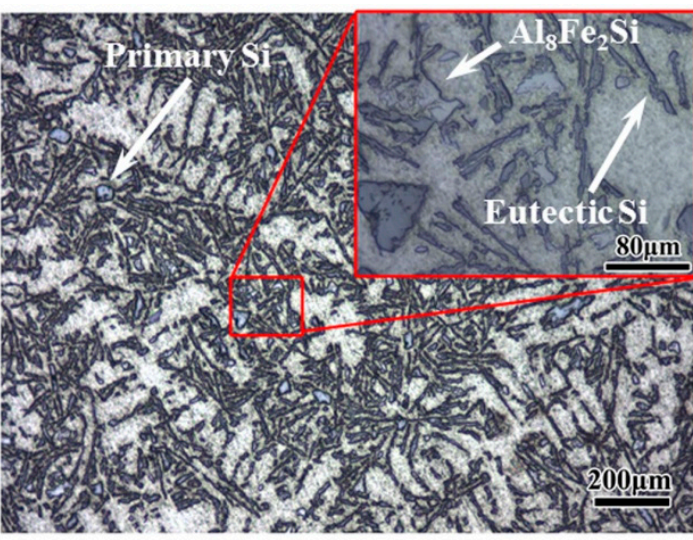

(a)

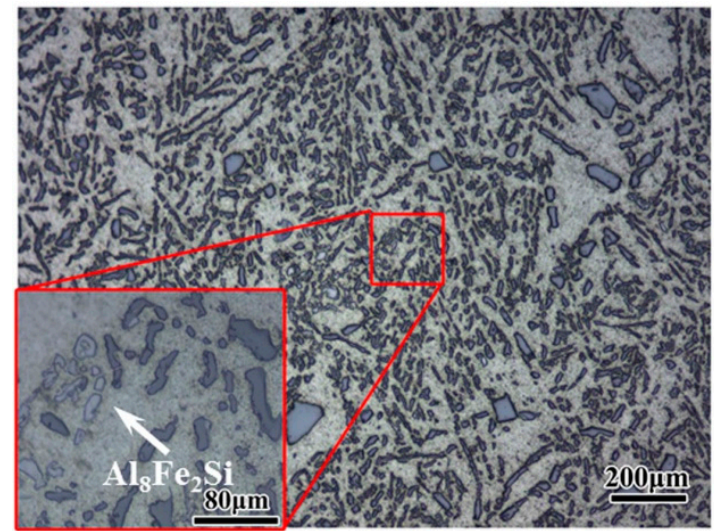

(c)

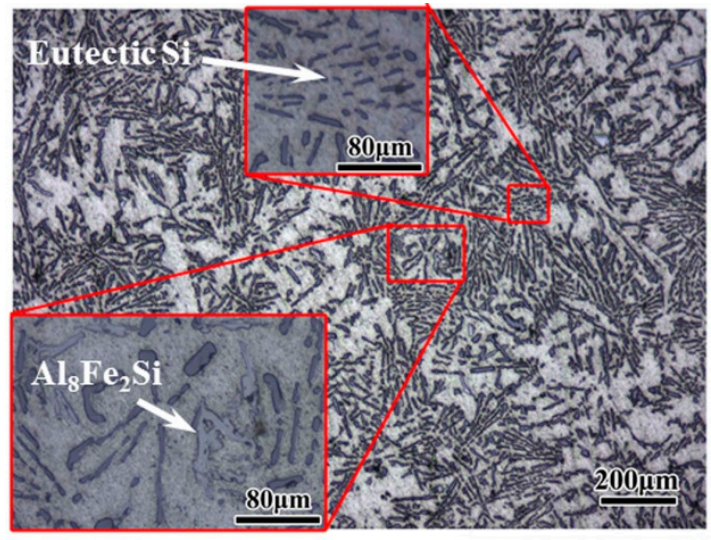

(b)

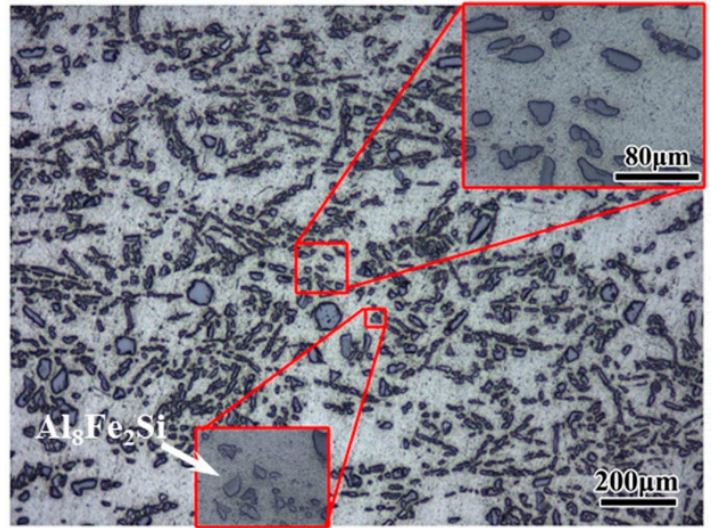

(d)

Figure 2. Metallographic images of the Al-Si-Fe alloys: (a) as-cast; (b) as-cast + T6; (c) as-rolled; and (d) as-rolled $+\mathrm{T} 6$.

After artificial T6 heat treatment, the needle-phase eutectic silicon particles in the Al-Si-Fe alloy appeared to break down and have a smooth edge, as shown in Figure $2 b$, and were still distributed along the original needle-like phase. The sizes of both the primary and eutectic silicon decreased compared with those of the as-cast samples, but nothing in the precipitated $\mathrm{Al}_{8} \mathrm{Fe}_{2} \mathrm{Si}$ phase changed, as marked in Figure $2 b$ by the arrow. Figure $2 c$ shows the microstructures of the Al-Si-Fe alloy after homogenization treatment and rolling. The needle-like eutectic-silicon particles and bulk primary silicon particles broke into fragments during the rolling process. In particular, the precipitated $\mathrm{Al}_{8} \mathrm{Fe}_{2} \mathrm{Si}$ phase was also broken, as marked by the arrow in the enlarged area of Figure 2c.

Compared with the as-cast Al-Si-Fe alloy, the distribution of the Si phase was more homogeneous, and the width of the Si phase was slightly larger in the as-rolled alloy due to the homogenization 
treatment before rolling. Furthermore, the edge of the Si phase was as rough as it was in the as-cast alloy. After the T6 heat treatment, the size of the Si phase shown in Figure 2d did not change markedly, but the morphology of the silicon particles tended to be spheroidized, due to their edges becoming smooth. Similarly, the T6 treatment had no effect on the precipitated $\mathrm{Al}_{8} \mathrm{Fe}_{2} \mathrm{Si}$ phase.

Moreover, the average length of the silicon particles was used instead of their actual size. The statistical results of the aspect ratio and average length of the eutectic silicon particles are represented in Figure 3. The aspect ratio and average length of the as-cast sample were 7.78 and $103.62 \mu \mathrm{m}$, compared to 2.81 and $39.19 \mu \mathrm{m}$ of the as-cast + T6 sample, respectively. After T6 heat treatment, the eutectic silicon dissolved in the matrix partly broke down and precipitated in the aluminum grains, which caused the aspect ratio and average length of the eutectic silicon to decrease significantly by blunting and fragmenting the needle-like silicon phases.

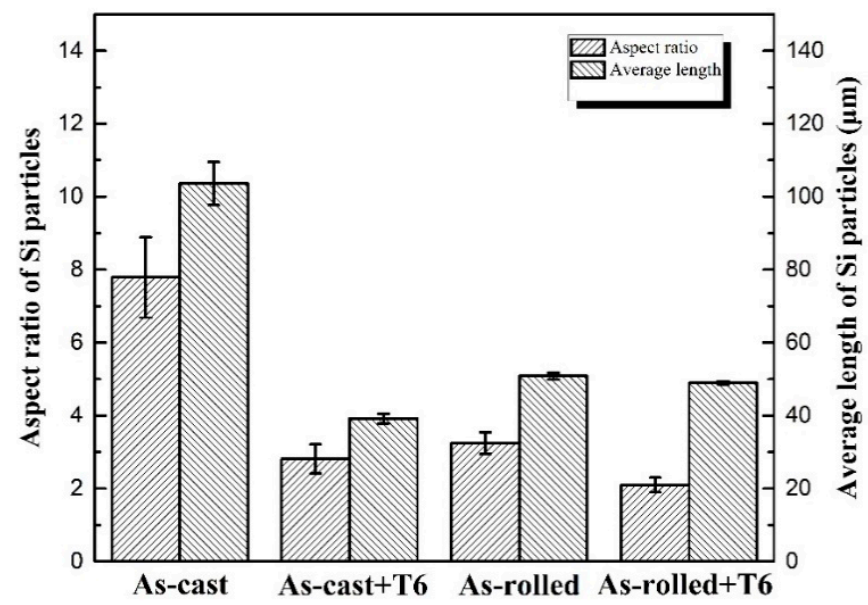

Figure 3. The aspect ratio and average length of the Si phase in Al-Si-Fe alloys prepared by different fabrication processes.

\subsection{Thermal Properties}

The microstructural features and thermal properties of the alloys fabricated by different processes are listed in Table 2. According to the morphology and average length of Si listed in the table, the differences in the thermal conductivity and thermal diffusivity among the different fabrication processes of the Al-Si-Fe alloys are mainly caused by the changes in the morphology of the Si phase. The thermal properties of the alloy improved as the Si-phase shape became closer to spherical and the boundary became smoother. By comparing the results of the thermal properties of the as-cast alloy and the as-rolled alloy with the T6 treatment, it is evident that a second factor was the size of the Si phase, and better thermal conductivity corresponded to smaller sizes of the Si phase. Moreover, there was no significant change in thermal properties despite fragmentation of the precipitated $\mathrm{Al}_{8} \mathrm{Fe}_{2} \mathrm{Si}$ phase, as illustrated in Figure 2c,d.

Table 2. Microstructural features and thermal properties of the Al-Si-Fe alloys under different fabrication processes.

\begin{tabular}{cccccc}
\hline & \multicolumn{2}{c}{ Microstructure } & \multicolumn{3}{c}{ Thermal Properties } \\
\cline { 2 - 6 } Treatment & $\begin{array}{c}\text { Morphology } \\
\text { (Eutectic Si) }\end{array}$ & $\begin{array}{c}\text { Average } \\
\text { Length } \\
(\mathbf{S i})(\boldsymbol{\mu m})\end{array}$ & $\begin{array}{c}\text { Specific Heat } \\
\text { Capacity } \\
(\mathbf{J} / \mathbf{k g} / \mathbf{K})\end{array}$ & $\begin{array}{c}\text { Thermal } \\
\text { Conductivity } \\
(\mathbf{W} /(\mathbf{m} \cdot \mathbf{K}) \mathbf{)}\end{array}$ & $\begin{array}{c}\text { Thermal } \\
\text { Diffusivity } \\
\left(\mathbf{m}^{\mathbf{2}} / \mathbf{s}\right)\end{array}$ \\
\hline As-cast & Needle-like & $103.62 \pm 5.9$ & $0.963 \pm 0.027$ & $155.99 \pm 0.18$ & $61.944 \pm 0.028$ \\
As-cast + T6 & Broken-needle & $39.19 \pm 1.3$ & $1.009 \pm 0.013$ & $188.82 \pm 0.39$ & $71.563 \pm 0.029$ \\
As-rolled & Block-shape & $50.85 \pm 0.9$ & $1.004 \pm 0.009$ & $170.24 \pm 0.22$ & $64.769 \pm 0.047$ \\
As-rolled + T6 & Near-spheroidal & $48.96 \pm 0.43$ & $1.012 \pm 0.019$ & $188.22 \pm 0.16$ & $71.043 \pm 0.058$ \\
\hline
\end{tabular}




\subsection{Mechanical Properties}

Similarly, the microstructural features and mechanical properties of the alloys fabricated by different processes are listed in Table 3. Furthermore, the stress-stain curves of the Al-Si-Fe alloys are illustrated in Figure 4, and the tensile test results are listed in Table 3. Combined, these results indicate that both the morphology and the size of the Si phase have a great influence on the strength of the Al-Si-Fe alloys, and the morphology of the Si phase has a major influence on the yield strength. In addition, the distribution of the $\mathrm{Si}$ phase and the morphology of the precipitated $\mathrm{Al}_{8} \mathrm{Fe}_{2} \mathrm{Si}$ phase also have an effect on the mechanical properties, especially elongation.

Table 3. Microstructural features and mechanical properties of the Al-Si-Fe alloys under different fabrication processes.

\begin{tabular}{cccccc}
\hline & \multicolumn{2}{c}{ Microstructure } & \multicolumn{2}{c}{ Mechanical Properties } \\
\cline { 2 - 6 } Treatment & $\begin{array}{c}\text { Morphology } \\
\text { (Eutectic Si) }\end{array}$ & $\begin{array}{c}\text { Average } \\
\text { Length } \\
(\mathbf{S i})(\boldsymbol{\mu m})\end{array}$ & $\begin{array}{c}\text { Tensile Test } \\
\text { Ultimate Tensile } \\
\text { Strength } \mathbf{( M P a )}\end{array}$ & $\begin{array}{c}\text { Yield Strength } \\
\mathbf{( M P a )}\end{array}$ & $\begin{array}{c}\text { Elongation } \\
\mathbf{( \% )}\end{array}$ \\
\hline As-cast & Needle-like & $103.62 \pm 5.9$ & $162.05 \pm 4.94$ & $122.56 \pm 6.45$ & $0.78 \pm 0.14$ \\
As-cast + T6 & Broken-needle & $39.19 \pm 1.3$ & $241.50 \pm 6.21$ & $239.37 \pm 5.57$ & $0.48 \pm 0.11$ \\
As-rolled & Block-shape & $50.85 \pm 0.9$ & $241.98 \pm 1.52$ & $203.27 \pm 3.29$ & $8.73 \pm 0.18$ \\
As-rolled + T6 & Near-spheroidal & $48.96 \pm 0.43$ & $295.21 \pm 2.38$ & $244.28 \pm 8.18$ & $9.56 \pm 0.23$ \\
\hline
\end{tabular}

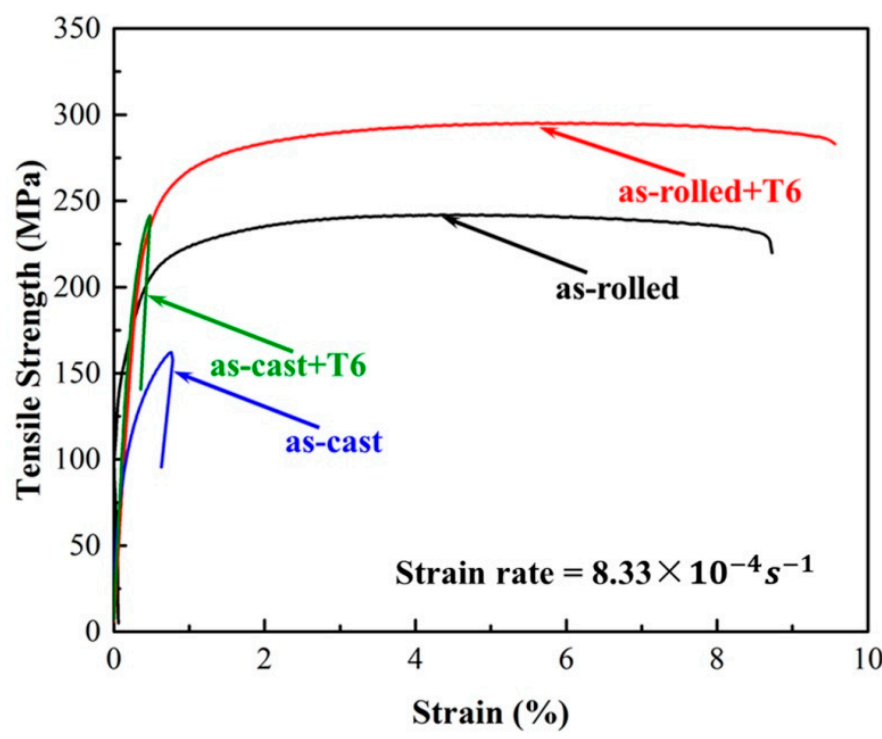

Figure 4. The stress-stain curves of the Al-Si-Fe alloys prepared by different fabrication processes.

Meanwhile, the results from the SEM images of the fracture morphologies exhibited in Figure $5 \mathrm{a}, \mathrm{b}$ indicate that the as-cast sample and as-cast + T6 sample both had cleavage fractures as many cleavage facets can be observed. Then, the fracture mechanism transitioned to quasi-cleavage fracture after rolling. Moreover, some dimples could be found in the as-rolled + T6 sample, as shown in Figure 5c,d, and the cleavage facets observed in the last two samples were very small. 

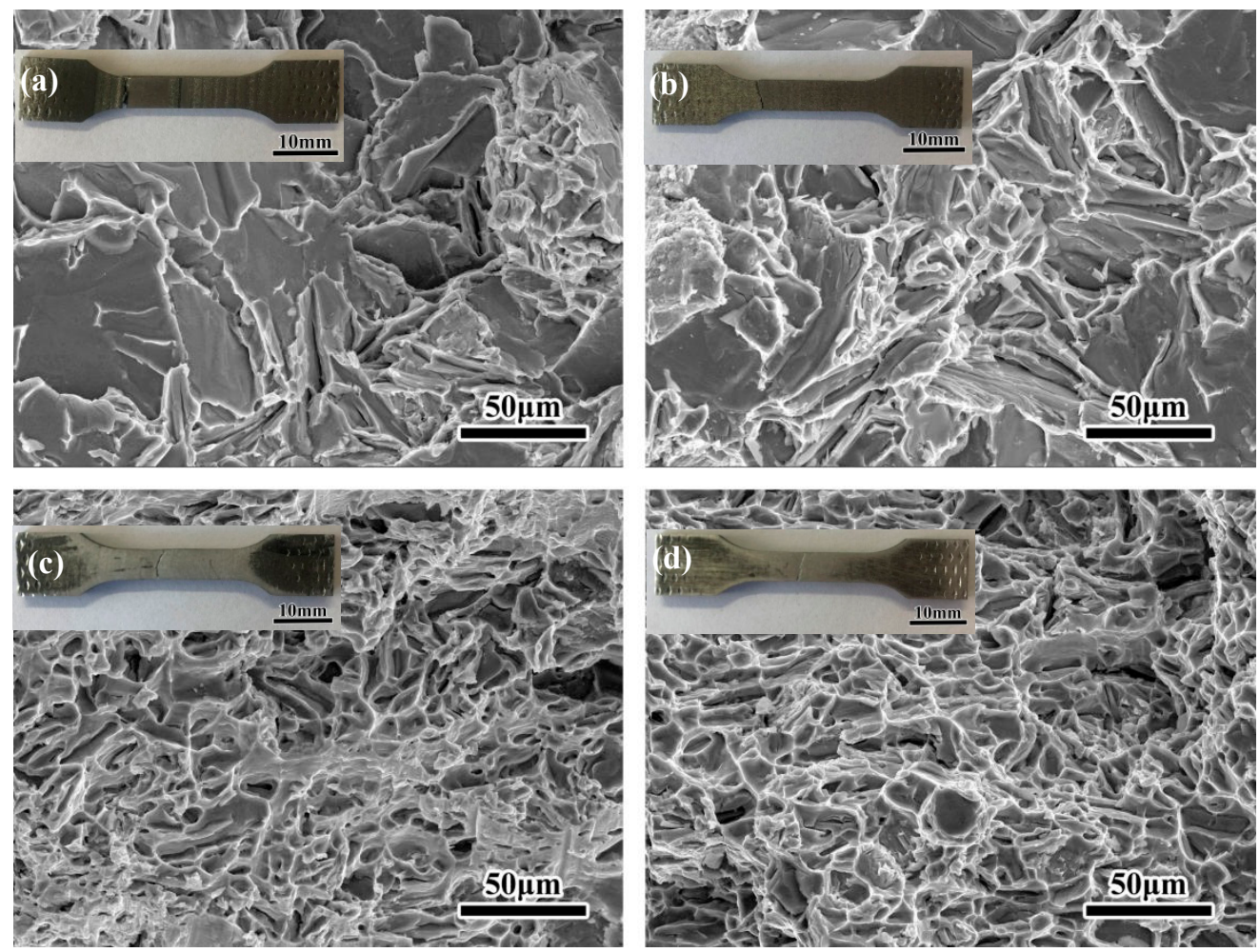

Figure 5. Fracture morphology of the Al-Si-Fe alloys prepared by different fabrication processes: (a) as-cast; (b) as-cast + T6; (c) as-rolled; and (d) as-rolled + T6.

\section{Discussion}

Based on the experimental results mentioned above, two factors-spheroidization and eutectic silicon particle size-play major roles in the thermal and mechanical properties of aluminum alloys $[9,16]$. Because the shapes of the eutectic silicon particles in as-cast and as-rolled samples are either needle-like or block-like, the aspect ratio was used to replace spheroidization for the characterization of silicon morphology. It is well-known that both the matrix phase and second phase fragment during the rolling process, which in this study reduced the average length of the silicon particles nearly as well as the T6 treatment did. Meanwhile, as an indispensable step in rolling processing, homogenization treatment mainly caused the spheroidization of the Si eutectic phases, solute redistribution, and the removal of micro-segregation [23], as well as solution treatment [24]. Although the fragmentation of the eutectic Si took place mostly at the early stage, solute redistribution and the removal of micro-segregation with a long-time homogenization treatment were beneficial to quality improvement of rolling microstructure. Thus, the silicon phase fragments also resulted in block shapes with low particle roundness. Due to the fragmentation of the needle-like silicon phase in the rolling process, the block-shaped silicon phase no longer fragmented during the solid solution stage but rather spheroidized [25]. Thus, compared with those in the as-rolled samples, the average length of silicon particles in the as-rolled + T6 samples barely changed, and the aspect ratio obviously decreased, as shown in Figure 2.

The changes of the thermal conductivity and the aspect ratio of the eutectic silicon with the heat treatment and rolling were investigated to examine the effect of spheroidization of the eutectic silicon particles. Because the aspect ratios of the Si phase in the as-rolled $+\mathrm{T} 6$ samples were lower than that in the as-cast $+\mathrm{T} 6$ samples, the thermal diffusivities of the as-cast $+\mathrm{T} 6$ samples were the same as those of the as-rolled + T6 samples, although the average lengths of the Si phase in the as-rolled + T6 samples were larger. Therefore, it seems that the decrease of aspect ratio due to the segregation and spheroidization of eutectic silicon made the thermal conductivity increase. As the thermal conduction 
of alloys at room temperature is mainly caused by the motion of electrons, the effect of low-density vacancies and dislocations on thermal conductivity can be neglected [26]. Thus, after heat treatment and rolling, the microstructural evolution of the silicon particles was considered to promote electron migration. Furthermore, although the as-cast + T6 samples had shorter average length and a slightly larger aspect ratio than those of the as-rolled + T6 samples, the thermal properties were still almost the same, which can be observed in Figure 3 and Table 2. This indicates that the aspect ratio of the Si phase played an important role in thermal conduction, as well as the average length, and suggests that thermal diffusivity is inversely proportional to the average length and aspect ratio of the eutectic silicon particles $[9,11]$. Remarkably, although the $\mathrm{Al}_{8} \mathrm{Fe}_{2} \mathrm{Si}$ phase was also fragmented during the rolling process, there was no significant change in the thermal properties, which seems to indicate that the average length of the $\mathrm{Al}_{8} \mathrm{Fe}_{2} \mathrm{Si}$ phase has no obvious effect on the thermal properties of the $\mathrm{Al}-\mathrm{Si}-\mathrm{Fe}$ alloys. This is mainly because of the lower quantity of precipitated $\mathrm{Al}_{8} \mathrm{Fe}_{2} \mathrm{Si}$ and $\mathrm{Mg}_{2} \mathrm{Si}$ phases and the larger interphase space between precipitated phases compared with the mean free path of electrons [27], thus the lower effect of the precipitated phases on the thermal properties.

Aluminum is more liable to dynamic recovery during severe plastic deformation (SPD) processing at high temperature, on account of its high stacking fault energy (SFE), which leads to fine-grained microstructure. Therefore, the strengthening mechanism in as-rolled samples could be dominated by grain boundary strengthening [28] and fine-grain strengthening. The mechanical property results indicated that the ultimate tensile strength and yield strength of as-rolled samples were enhanced by the classical Hall-Petch effect, due to $\alpha$-Al matrix refinement and uniform distribution of the fine spherical-shaped Si particles. The mechanical property results of the samples with and without T6 treatment showed that the Orowan strengthening introduced by T6 treatment mainly led to the improvement of ultimate tensile strength. The $\mathrm{T} 6$ treatment resulted in the dissolution of coarse $\mathrm{Mg}_{2} \mathrm{Si}$ in as-cast sample and the re-precipitation of fine $\mathrm{Mg}_{2} \mathrm{Si}$, and therefore led to an increase in strength and a reduction in ductility. The coarse acicular Si particles and brittle Fe-rich intermetallics may also have caused the lowest elongation in as-cast $+\mathrm{T} 6$ samples, which always result in the nucleation of cracks. On the other hand, the presence of cast porosity can also cause premature fracture [29]. Comparing Figure $5 a, c$, the large cleavage facets in the as-cast sample became small cleavage facets after rolling. The elongation increase in as-rolled samples could also be caused by the elimination of casting porosities, refinement of the $\alpha$-Al grain size, and homogeneous distribution of silicon particles with low aspect ratio during the rolling process [30], because the premature failure caused by the thick needle-shaped silicon phase can be avoided. Although the spheroidized eutectic silicon particles can reduce the premature failure, the coarse primary silicon cannot fragment during solution treatment. Thus, the as-cast $+\mathrm{T} 6$ samples with the reduced aspect ratio of silicon particles were still cleavage fractured and had poor elongation. The fracture surface of as-cast alloy after T6 heat treatment (as shown in Figure 5b) also had more tear ridges and cleavage facets. Furthermore, the elongation of as-cast and as-rolled samples was almost unchanged after the T6 treatment, which also reveals that the average length of silicon particles has little effect on elongation.

\section{Conclusions}

In the present study, the effects of a rolling process and T6 heat treatment on the microstructure and mechanical and thermal properties of an Al-Si-Fe alloy were investigated, and the following conclusions were obtained:

1. The thermal properties, including the thermal conductivity and thermal diffusivity of the Al-Si-Fe alloy, were mainly affected by the morphology of the silicon phase. A smaller average length and aspect ratio for the silicon phase could improve the thermal properties of the alloy. However, the morphology of the precipitated $\mathrm{Al}_{8} \mathrm{Fe}_{2} \mathrm{Si}$ phase had no evident effect on the thermal properties.

2. The average length and aspect ratio of the silicon particles could influence the ultimate tensile strength of Al-Si-Fe alloys. The improvement of the elongation of the alloy was mainly caused by 
matrix grain refinement and spheroidization of the silicon particles, but the average length of silicon particles had no effect on elongation.

3. The thermal conductivity of the Al-Si-Fe alloy fabricated by rolling with a T6 treatment was $188.22 \mathrm{~W} /(\mathrm{m} \cdot \mathrm{K})$, which exceeded by 1.2 times that of the as-cast Al-Si-Fe alloy. The final tensile strength, yield strength, and elongation were $244.28 \mathrm{MPa}$, 295.21 MPa, and 9.56\%, respectively.

Author Contributions: Y.G., Y.W. and J.Y. conducted the experiments. Y.G., Y.W. and H.X. discussed the results and analysis and wrote the manuscript. M.H. and Z.J. cooperated in the experiments.

Funding: This research was funded by National Natural Science Foundation of China (Grant No. 51801045).

Conflicts of Interest: The authors declare no conflict of interest.

\section{References}

1. Li, Z.; Samuel, A.M.; Samuel, F.H.; Ravindran, C.; Valtierra, S.; Doty, H.W. Parameters Controlling the performance of AA319-type alloys: Part I. tensile properties. Mater. Sci. Eng. A 2004, 367, 96-110. [CrossRef]

2. Jamaati, R.; Amirkhanlou, S.; Toroghinejad, M.R.; Niroumand, B. Significant improvement of semi-solid microstructure and mechanical properties of A356 alloy by ARB process. Mater. Sci. Eng. A 2011, 528, 2495-2501. [CrossRef]

3. Jeong, C.Y. High temperature mechanical properties of $\mathrm{Al}-\mathrm{Si}-\mathrm{Mg}-(\mathrm{Cu})$ alloys for automotive cylinder heads. Mater. Trans. 2013, 54, 588-594. [CrossRef]

4. Yao, J.Y.; Taylor, J.A. Characterisation of intermetallic particles formed during solution treatment of an Al-7Si-0.4Mg-0.12Fe alloy. J. Alloys Compd. 2012, 519, 60-65. [CrossRef]

5. Ammar, H.; Samuel, A.; Samuel, F.; Simielli, E.; Sigworth, G.; Lin, J. Influence of aging parameters on the tensile properties and quality index of Al-9 Pct Si-1.8 Pct Cu-0.5 Pct Mg 354-Type casting alloys. Metall. Mater. Trans. A 2012, 43, 61-73. [CrossRef]

6. Zhao, Q.R.; Cui, X.L.; Qian, Z.; Liu, X.F. The synergistic effect of Al-B-C master alloy to improve conductivity and strength of 1070 alloy. J. Alloys Compd. 2015, 639, 478-482. [CrossRef]

7. Lumley, R.N.; Deeva, N.; Larsen, R.; Gembarovic, J.; Freeman, J. The role of alloy composition and T7 heat treatment in enhancing thermal conductivity of aluminum high pressure diecastings. Metall. Mater. Trans. A 2012, 44, 1074-1086. [CrossRef]

8. Chen, J.K.; Hung, H.Y.; Wang, C.F.; Tang, N.K. Thermal and electrical conductivity in Al-Si/Cu/Fe/Mg binary and ternary Al alloys. J. Mater. Sci. 2015, 50, 5630-5639. [CrossRef]

9. Choi, S.W.; Kim, Y.M.; Lee, K.M.; Cho, H.S.; Hong, S.K.; Kim, Y.C.; Kang, C.S.; Kumai, S. The effects of cooling rate and heat treatment on mechanical and thermal characteristics of Al-Si-Cu-Mg foundry alloys. J. Alloys Compd. 2014, 617, 654-659. [CrossRef]

10. Choi, S.W.; Cho, H.S.; Kang, C.S.; Kumai, S. Precipitation dependence of thermal properties for Al-Si-Mg-Cu-(Ti) alloy with various heat treatment. J. Alloys Compd. 2015, 647, 1091-1097. [CrossRef]

11. Kim, Y.M.; Choi, S.W.; Hong, S.K. The behavior of thermal diffusivity change according to the heat treatment in Al-Si binary system. J. Alloys Compd. 2016, 687, 54-58. [CrossRef]

12. Choi, S.W.; Cho, H.S.; Kumai, S. Effect of the precipitation of secondary phases on the thermal diffusivity and thermal conductivity of Al-4.5Cu alloy. J. Alloys Compd. 2016, 688, 897-902. [CrossRef]

13. Stadler, F.; Antrekowitsch, H.; Fragner, W.; Kaufmann, H.; Pinatel, E.R.; Uggowitzer, P.J. The effect of main alloying elements on the physical properties of Al-Si foundry alloys. Mater. Sci. Eng. A 2013, 560, 481-491. [CrossRef]

14. Wu, Y.N.; Zhang, J.F.; Liao, H.C.; Wang, Y.J.; Wu, Y.P. Effect of homogenization temperature on microstructure and conductivity of Al-Mg-Si-Ce alloy. J. Mater. Eng. Perform. 2016, 25, 2720-2726. [CrossRef]

15. Zhang, C.; Du, Y.; Liu, S.H.; Liu, S.J.; Jie, W.Q.; Sundman, B. Microstructure and thermal conductivity of the as-cast and annealed $\mathrm{Al}-\mathrm{Cu}-\mathrm{Mg}-\mathrm{Si}$ alloys in the temperature range from $25^{\circ} \mathrm{C}$ to $400{ }^{\circ} \mathrm{C}$. Int. J. Thermophys. 2015, 36, 2869-2880. [CrossRef]

16. Lumley, R.N.; Polmear, I.J.; Groot, H.; Ferrier, J. Thermal characteristics of heat-treated aluminum high-pressure die-castings. Scr. Mater. 2008, 58, 1006-1009. [CrossRef] 
17. Chen, J.K.; Hung, H.Y.; Wang, C.F.; Tang, N.K. Effects of casting and heat treatment processes on the thermal conductivity of an Al-Si-Cu-Fe-Zn alloy. Int. J. Heat Mass Transf. 2017, 105, 189-195. [CrossRef]

18. Wang, Y.; Liao, H.; Wu, Y.; Yang, J. Effect of Si content on microstructure and mechanical properties of Al-Si-Mg alloys. Mater. Des. 2014, 53, 634-638. [CrossRef]

19. Adamczyk-Cieślak, B.; Mizera, J.; Kurzydłowski, K.J. Microstructures in the 6060 aluminium alloy after various severe plastic deformation treatments. Mater. Charact. 2011, 62, 327-332. [CrossRef]

20. Liao, H.C.; Wu, Y.N.; Wang, Y.J. Microstructure evolution of Al-0.35\%Si-0.2\%Mg-0.3\%Ce alloy during hot extrusion and its contributions to performances. J. Mater. Eng. Perform. 2015, 24, 2503-2510. [CrossRef]

21. Morozova, A.; Mogucheva, A.; Bukin, D.; Lukianova, O.; Korotkova, N.; Belov, N.; Kaibyshev, R. Effect of Si and $\mathrm{Zr}$ on the microstructure and properties of Al-Fe-Si-Zr alloys. Metals 2017, 7, 495. [CrossRef]

22. Zhao, Q.R.; Qian, Z.; Cui, X.L.; Wu, Y.Y.; Liu, X.F. Influences of Fe, Si and homogenization on electrical conductivity and mechanical properties of dilute Al-Mg-Si alloy. J. Alloys Compd. 2016, 666, 50-57. [CrossRef]

23. Sadeghi, I.; Wells, M.A.; Esmaeili, S. Modeling homogenization behavior of Al-Si-Cu-Mg aluminum alloy. Mater. Des. 2017, 128, 241-249. [CrossRef]

24. Lados, D.A.; Apelian, D.; Wang, L.B. Solution treatment effects on microstructure and mechanical properties of Al-(1 to 13 pct)Si-Mg cast alloys. Metall. Mater. Trans. B 2011, 42B, 171-180. [CrossRef]

25. Sharma, R.; Anesh; Dwivedi, D.K. Influence of silicon (wt.\%) and heat treatment on abrasive wear behaviour of cast Al-Si-Mg alloys. Mater. Sci. Eng. A 2005, 408, 274-280. [CrossRef]

26. Li, B.C.; Hou, L.; Wu, R.Z.; Zhang, J.H.; Li, X.L.; Zhang, M.L. Microstructure and thermal conductivity of Mg-2Zn-Zr alloy. J. Alloys Compd. 2017, 722, 772-777. [CrossRef]

27. Ying, T.; Zheng, M.Y.; Li, Z.T.; Qiao, X.G. Thermal conductivity of as-cast and as-extruded binary Mg-Al alloys. J. Alloys Compd. 2014, 608, 19-24. [CrossRef]

28. Panigrahi, S.K.; Jayaganthan, R.J. Development of ultrafine grained high strengthage hardenable Al 7075 alloy by cryorolling. Mater. Des. 2011, 32, 3150-3160. [CrossRef]

29. Gurua, P.R.; Khan MD, F.; Panigrahia, S.K.; Janaki Ramb, G.D. Enhancing strength, ductility and machinability of a Al-Si cast alloy by friction stir processing. J. Manuf. Process. 2015, 18, 67-74. [CrossRef]

30. Immanuel, R.J.; Panigrahi, S.K. Influence of cryorolling on microstructure and mechanical properties of a cast hypoeutectic Al-Si alloy. Mater. Sci. Eng. A 2015, 640, 424-435. [CrossRef] 